\title{
EL VERDADERO HERMETISMO DE CERVANTES
}

Que lo que Cervantes escribe no se agota en su sentido literal es idea de larga y justa vigencia entre cervantistas, aunque lo que Cervantes oculta y cómo lo hace parecen muy distinto, por ejemplo, en Díaz de Benjumea y en Joaquín Casalduero. Las líneas que siguen proponen una aproximación nueva a la perenne cuestión.

En un par de líneas del capítulo 12 del libro 3 del Persiles y Segismunda, última novela de Cervantes, una dama dice llamarse Ambrosia Agustina y Bernardo Agustín su al parecer único hermano. A estudiosos de historia de la Iglesia esta reunión de nombres debe resultarles sugestiva. Pues san Ambrosio, san Agustín y san Bernardo son un famoso trío de doctores, personalmente relacionados entre sí los dos primeros, que vivieron en el siglo IV, y confeso discípulo incondicional de ambos el tercero, del siglo XII ${ }^{1}$.

Tal relación histórica entre los santos doctores haría ya pensar que la apretada reunión de sus nombres en el Persiles no es casual. Pero para pensarlo hay más razones.

Los tres santos han sido muy invocados juntos por luteranos y católicos luteranizantes en apoyo de la justificación por la sola fe, doctrina capital de Lutero. Podría aquí evocárselos, con disimulo explicable, en esa o análoga función.

Pero hay más. El enamorado de Ambrosia Agustina lleva, en la línea que en la novela sigue, el insólito nombre de Contarino. Esta es una forma española del apellido del más importante cardenal del pontificado de Paulo III, Gaspar Contarini (1483-1542), a quien algunos atribuían la autoría del famoso tratadito luterocatólico Del Beneficio de Cristo crucificado, donde los tres doctores más citados en apoyo de la justificación por la sola fe son precisamente san Ambrosio, san Agustín y san Bernardo. ¿Es fácil creer que el nombre Contarino se agrega a los de los tres doctores por mero azar??2

${ }^{1}$ Cf. Obras completas de San Bernardo, BAC, Madrid, 1953, p. 7.

${ }^{2}$ Del Beneficio de Cristo hay edición de La Aurora, Buenos Aires, 1953. Allí las citas de san Agustín ocupan 44 líneas, 41 las de san Ambrosio y 23 las de san Bernardo. 
Hay quienes aman la elocuencia de los números. El solo santoral católico propone, por cierto, más de mil nombres de pila diferentes. Hay muchos otros, como Absalón, Aquiles, Diana, que no vienen del santoral. Y Cervantes, para más, crea nombres, como Quijote y Dulcinea, cada vez que se le antoja. Pero si, favoreciendo mucho al azar, suponemos que Cervantes sólo hubiese tenido mil nombres para elegir entre ellos, la probabilidad matemática de que eligiera por azar, uno a uno aquellos cuatro se expresaría, según el cálculo combinatorio, en un quebrado que tuviese por numerador $1 \times 2 \times 3 \times 4$ y por denominador $1000 \times$ $999 \times 998 \times 997$, lo que nos daría, al cabo, uno sobre más de cuarenta y un mil millones. ¿Cómo distinguir entre esto y la imposibilidad total del encuentro de los cuatro nombres por azar?

Lo cuerdo es, sin disputa, tener ese encuentro por querido por Cervantes, y es sensato, además si no se halla explicación mejor, pensar que reunió los cuatro nombres para que intuyésemos en Contarino al cardenal Contarini y en los nombres Ambrosia, Agustín y Bernardo al Beneficio de Cristo, que tan destacadamente los cita, como obra suya. Y si no, a Contarini y al catolicismo luteranizante que demostró en sus actos - como veremos- y sus escritos auténticos. (E1 Beneficio de Cristo no es en realidad suyo.)

Queda así expuesta una alusión histórica segura y bastante precisa disimulada en un texto de Cervantes. Y una alusión disimulada a Contarini y su doctrina empuja a presumir en su contexto inmediato un desarrollo oculto en relación con esos temas para integrar un probable relato encubierto de historia religiosa tabú.

Que el contexto parezca hablar de otras cosas lleva a conjeturar que Cervantes configura sus alusiones con algún auxilio de un código, que sería consabido en su ambiente. Nuestras matemáticas hacen difícil dudarlo, y hay por lo menos un texto de un contemporáneo que, respetado y razonado como se debe, atestiguaría uso de código en Cervantes. Es el famoso pasaje del prólogo del Quijote apócrifo que le atribuye "ostentación de sinónimos voluntarios".

Una interpretación prejuiciosa ha venido convirtiendo esos sinónimos en seudónimos, homónimos, apodos, etc., cuando lo lógico era ver en ellos "sinónimos artificiales", hechos sinónimos por voluntad de un grupo interesado en la elaboración de mensajes incomprensibles para los extraños. Ese grupo usaría, como es de sospechar en Cervantes, un código, cada voz del cual sería un secreto sinónimo convenido, voluntario, de la palabra a la que reemplaza y esconde. Es el único sentido lógico de la frase tal cual es.

Las de los otros doctores citados tienen menos lugar. La atribución del libro a Contarini consta en la Historia de los heterodoxos españoles, de Menéndez y Pelayo (lib. 4, cap. 4, p. iv. En la ed. Emecé, Buenos Aires, 1945, t. 4, p. 278). 
Veamos ahora si el contexto en que sospechamos historia encubierta nos deja percibir algo que secretee de Contarini, su historia o su doctrina; tal vez hasta hallemos así voces con sentido de código probable. El Persiles narra que Contarino, enamorado de Ambrosia Agustina, se casa con ella, y -dice la dama:

el mismo día que le di la mano recibió él de la de Su Majestad una carta, en que le mandaba viniese luego al punto a conducir un tercio... de infantería española, a la isla de Malta, sobre la cual se pensaba bajaba el turco. Obedeció Contarino con tanta puntualidad lo que se le mandaba que... sin tener en cuenta con mis lágrimas, el recibir la carta y el partirse todo fue uno ${ }^{3}$.

Siendo claro que Contarino disfraza al cardenal Contarini, la carta en que Su Majestad le ordena partir al punto en su auxilio parece pensada para encaminar al lector en forma decisiva recordando sin velos un real llamado urgente de S. M. el emperador Carlos V a Contarini, hecho capital en la historia de éste.

A principios de 1541 el papa Paulo III, a cuyo lado estaba Contarini, recibió, en efecto, de ministros de Carlos V, por voluntad indudable de éste, urgentes mensajes para que enviase sin demora a Contarini como legado suyo ante el Coloquio de Ratisbona, en el que Carlos esperaba que católicos y protestantes hallasen una fórmula teológica que reconciliase a los dos bandos. Pero su esperanza parecía en aquel momento amenazada por la inevitable y ya muy real presencia en el coloquio del máximo contradictor alemán de Lutero, el muy intransigente teólogo católico Juan Eck. Conforme al deseo imperial, Contarini fue a Ratisbona como legado, presurosamente, con especial encargo de contener el afán polémico de Eck, a quien en efecto contendrá ${ }^{4}$.

El urgente llamado imperial a Contarini, decíamos, se enuncia en el Persiles sin velos. Pero ¿no es inevitable suponer que el real motivo del llamado también se exprese, con previsible disimulo? ¿'No será el amenazante turco del Persiles un disfraz, quizá un "sinónimo voluntario", de católicos como Eck que amenazaban frustrar la concordia? ¿No será Malta, histórico bastión cristiano ante los turcos, un concordante disfraz del coloquio, donde del lado católico sólo esta-

${ }^{3}$ Cito, por la ed. A. Valbuena Prat, en Obras completas, Aguilar, Madrid, t. 2; esta cita y las siguientes, en p. 1022.

${ }^{4}$ Los coloquios conciliadores y en especial el de Ratisbona de 1541 se tratan con extensión en el cap. 5 del t. 11 de la Historia de los Papas de L. PAstor (Gili, Barcelona, 1953). Sobre los opuestos papeles de Contarini y Eck interesan allí en especial las pp. 362, 364, 373-374, 378-379. El acuerdo logrado en la doble justificación, luterana y católica reunidas, quedó sin efecto al disolverse poco después el coloquio. 
rían, además de Eck, los luteranizantes Juan Gropper y Julio Pflug?55 . Y este par de disfraces explicaría también por qué el Contarino del Persiles es "caballero del hábito de Alcántara", una orden creada en la España medieval para luchar contra musulmanes. Los tres disfraces implicarían -y tengo muy visto que implican - una figuración convencional del catolicismo intransigente en musulmanes y del catolicismo luteranizante en los cristianos.

Que Cervantes use código suena hoy tan absurdo que me siento obligado aquí a un paréntesis que lo haga quizás menos increíble.

He descrito en un libro reciente, La criptorreforma jesuita y el gran arte críptico (El Copista, Córdoba, Argentina, 1999) el lenguaje críptico que encuentro en Cervantes y muchos otros. El código que lo integra, libremente ampliable sobre bases lógicas, es riquísimo en vocablos que, con matices dependiendo del contexto, casi sólo denotan relación por la justificación católica por las obras o relación con la justificación luterana por la fe, del modo ejemplificado arriba en las voces turco y Malta.

El código sólo ayuda, pues, a configurar alusiones relativas a la máxima cuestión de la época: la de catolicismo o protestantismo. Pero lo hace permitiendo, con su extraordinaria riqueza y flexibilidad, en el sabio lenguaje críptico que integra, la más amplia libertad creadora en el terreno del arte. Mi libro incluye, amén de otras cosas, mi desciframiento del episodio de Ambrosia y de varios del Quijote con razonable apoyo de nombres propios.

Cerrando aquí mi paréntesis, vuelvo a mi anterior andar, sin servirme del código, en lo que sigue.

La carta de Su Majestad ordena a Contarino conducir "un tercio... de infantería española”. En esta infantería es difícil no sospechar figurada a la Compañía de Jesús, milicia a lo divino que en septiembre de 1540, tres meses antes del viaje de Contarini (enero de 1541), había sido aprobada por el papa a instancias de él. Pareciera decirse, pues, que la Compañía o algo de ella tuvo que ver con la misión de Contarini.

Este así insinuado vínculo de la Compañía y Contarini lleva a preguntarnos si Ambrosia Agustina, la amada de Contarino, no figurará también a la Compañía de Jesús. Contarino se enamora de ella como Contarini se prendó de la Compañía al conocer en Roma a Loyola, en $1538^{6}$. Contarino parte llamado por Su Majestad el mismo día de la boda como Contarini parte llamado por Carlos $\mathrm{V}$ a sólo tres meses de aprobada por el papa su dilecta Compañía. Y Ambrosia derrama lágrimas por el alejamiento de Contarino como el viaje de Contarini a Ratisbona apesadumbró a los jesuitas, según sabemos por la cons-

${ }^{5}$ Cf. PASTOR, op. cit., t. 11, p. 377.

${ }^{6}$ Véase Obras completas de S. Ignacio de Loyola, BAC, Madrid, 1947, t. 1, p. 537. 
ternación - ¿por la doctrina, la forma, la oportunidad?_- con que el jesuita Pedro Fabro comunicaba en carta a Loyola el avance de la doble justicia en el coloquio ${ }^{7}$.

Ambrosia sigue diciendo: "Pocos días pasaron, cuando, añadiendo yo imaginaciones a imaginaciones y deseos a deseos, vine a poner en efecto uno cuyo cumplimiento, así como me quitó la honra por entonces, pudiera también quitarme la vida”.

En nuestra hipótesis, Ambrosia hablaría aquí de una conducta de la Compañía que la habría desacreditado y puesto en peligro su vida. Lo cual ocurrió realmente a la orden, a entender de muchos, incluso al parecer Cervantes, en 1559, cuando por toda España circuló el rumor de que los jesuitas eran "autores y maestros" de las herejías protestantes descubiertas desde 1557 y que la inquisición reprimió con estrangulamientos y quemas de decenas de herejes en Valladolid y Sevilla en 1559 y $1560^{8}$. La inquisición sospechó entonces tanto de los jesuitas que el que es hoy San Francisco de Borja, delegado del general de la orden, tuvo que huir a Portugal para no ser prendido y procesado. Muchos pensaron entonces, incluso jesuitas, que la orden sería suprimida ${ }^{9}$.

Los "pocos días" que habrían pasado entre el coloquio de 1541 y las herejías de 1557-1559 serían sólo un modo de disfrazar lapsos de historia reduciéndolos a lapsos de novela; poco más arriba dos hechos separados por sólo tres meses se dicen ocurridos "el mismo día".

Ambrosia sigue así su historia: "Ausentéme de mi casa sin sabiduría de ninguno de ella, y, en hábitos de hombre... asenté por criado de un atambor de una compañía que estaba en un lugar, pienso que ocho leguas del mío".

Parecería hablarse aquí de cierto disfraz -¿no huele a código el disfraz de hombre?-, cierto disimulo de los jesuitas tras los sofocones de 1559, y armonizaría con eso el paso de Ambrosia a integrar una compañia "que estaba en un lugar pienso que ocho leguas del mío". ¿No podría decir esto, con la imagen más transparente, que los jesuitas del comienzo integraban ahora una Compañía de Jesús alejada de su posición originaria?

Lo cual parece otro modo de decir, como Marcel Bataillon dice en Erasmo y España, que después de 1559 "los jesuitas supieron librarse muy pronto de la sospecha de iluminismo que suscitaba la exalta-

7 Cf. Feliciano Cereceda S. I., Diego Laínez en la Europa religiosa de su tiempo, Madrid, 1946, t. 2, p. 244.

${ }^{8}$ Sobre el rumor, Pedro de Ribadeneyra S. I., Vida del P. Francisco de Borja, lib. 2, cap. 19. (En Historias de la Contrarreforma, BAC, Madrid, 1945, p. 740.) De los brotes luteranizantes españoles de 1558 habla Menéndez y Pelayo en los caps. 7, 8 y 9 del libro 4 de su Historia de los heterodoxos españoles.

${ }^{9}$ Sobre la fuga de Borja y el descrédito y presuntos peligros de la Compañía, incluso el de su disolución, CERECEDA, op. cit., t. 2, pp. 11-14 y t. 1, pp. 413-414. 
ción de la fe y de la gracia”, es decir la simpatía que habían dejado traslucir por la justificación luterana por la sola fe y pura gracia ${ }^{10}$. Su nueva tendencia fructificaría pronto en el "pelagiano" molinismo.

Lo que hemos empezado a ver de la historia de Ambrosia hace sospechar en ella una crónica religiosa secreta de la Compañía de Jesús (y, con otras comprobaciones para mí decisivas, es realmente eso). La compañía que Ambrosia integra protagoniza los párrafos del relato que inmediatamente siguen.

La Compañía de Jesús era muy tentadora como tema para tratarse a la sordina. Consta que en 1546 se murmuraba en España que los jesuitas enseñaban una doctrina secreta ${ }^{11}$. Ignacio de Loyola, fundador de la orden, fue objeto de varias pesquisas y hasta de dos juicios formales por sospechas de herejía12. Pese a las aprobaciones papales, su orden y sus ejercicios espirituales fueron denunciados con insistencia como heréticos, sobre todo en España por el gran teólogo Melchor Cano ${ }^{13}$. El cardenal Silíceo, arzobispo primado de Toledo, prohibió en 1551 el oficio de confesores a los sacerdotes que hubiesen hecho los ejercicios de Loyola y amenazó con excomunión mayor a los que se confesasen con un jesuita o recibiesen otro sacramento de sus manos ${ }^{14}$. Poco después vino lo arriba dicho de 1559 , que culminó en la fuga de Borja y el temor de que la orden sería suprimida.

Lo que sigue del relato de Ambrosia se presta menos a interpretación sin código, por lo que me detengo aquí. Resumiendo:

1. Nuestras consideraciones sobre los cuatro nombres prueban que un texto de Cervantes se refiere en secreto a un personaje histórico, el cardenal Gaspar Contarini, y a su catolicismo un poco luterano.

2. Esa referencia oculta hace presumir en su contexto un desarrollo, también oculto, en relación con ese tema. Lo cual sería imposible sin auxilio de un código que enmascarase el asunto.

3. El uso de código por Cervantes parece atestiguado en los "sinónimos voluntarios" que le atribuye el prólogo del Quijote apócrifo. Un oportuno empleo de la imaginación permite, en sana ciencia, conjeturar voces de código en el urgido viaje de Contarino, personaje de la novela, cotejado con el urgido viaje a Ratisbona del cardenal Contarini.

10 Marcel Bataillon, Erasmo y España, trad. Antonio Alatorre, F.C.E., México, 1950, t. 2, p. 372.

11 Cereceda, op. cit., t. 2, p. 7.

12 Véase persecuciones en el índice alfabético del t. 1 de las Obras dichas en nota 6, donde se enumeran ocho "procesos" investigando a Loyola.

13 Véase Cereceda, op. cit., t. 1, cap. 10, con las explicaciones jesuitas, que creo erradas

14 Cf. Pedro de Ribadeneyra S. I., Vida del bienaventurado Padre Ignacio de Loyola, lib. 4, cap. 4. (En Historias de la Contrarreforma, p. 272.) 
4. Vistas las comprobaciones procedentes, la posición y la calidad de las coincidencias arriba señaladas entre el relato novelesco de Ambrosia Agustina y la historia de la Compañía de Jesús autorizan la hipótesis de que la historia de Ambrosia cifre la de la Compañía. Añade fuerza a esta hipótesis el ser desde su origen la Compañía un tema cargado de enigma, de sospechas y de pasión polémica. Un tema de máximo interés, pero que, pasada la crisis de 1559 , se prohibió, sin duda, tratar con la necesaria libertad.

Carlos Alberto Moreyra 